\title{
Analysis of factors affecting the security of digital archives information in colleges and universities and countermeasures
}

\author{
Sha Li \\ Headmaster's office, Shandong University of Arts, Shandong Jinan, China, 250014
}

Keywords: university; digital; archive information; security

\begin{abstract}
With the continuous progress of science and technology and the acceleration of office automation, the construction of university digital archives informatization has developed to a new historical stage. The construction of university archives digitization is an important content of the construction of digitized campus, and also an important sign to measure the development level of university archives. However, with the development of archives informatization, the information security of university digital archives is facing severe challenges. This paper analyzes the influencing factors of the information security of the digital archives in colleges and universities, and then puts forward the corresponding countermeasures, in order to improve the comprehensive management level of archives and provide efficient and comprehensive service for teachers and students in colleges and universities.
\end{abstract}

\section{Introduction}

File digitization is a new type of archive information generated with the development of computer network technology, database technology and scanning technology. Nowadays, from the highest level of the country to the popularization of various grassroots levels and the rapid development of science and technology, the digitization of archives has become a very important form of archives information management in colleges and universities. However, with the gradual improvement of the degree of informationization of archives, the popularization of digital construction has made the security of digital archives in colleges and universities face severe challenges. Therefore, this has become the primary problem that urgently needs to be solved in the construction of college archives ${ }^{[1]}$.

\section{Factors affecting the security of digital archives in colleges and universities}

At present, the factors affecting the information security of digital archives in colleges and universities mainly include the following aspects, including the weak awareness of information security, rampant network malicious codes such as Trojan virus and weak talent team in file management. 


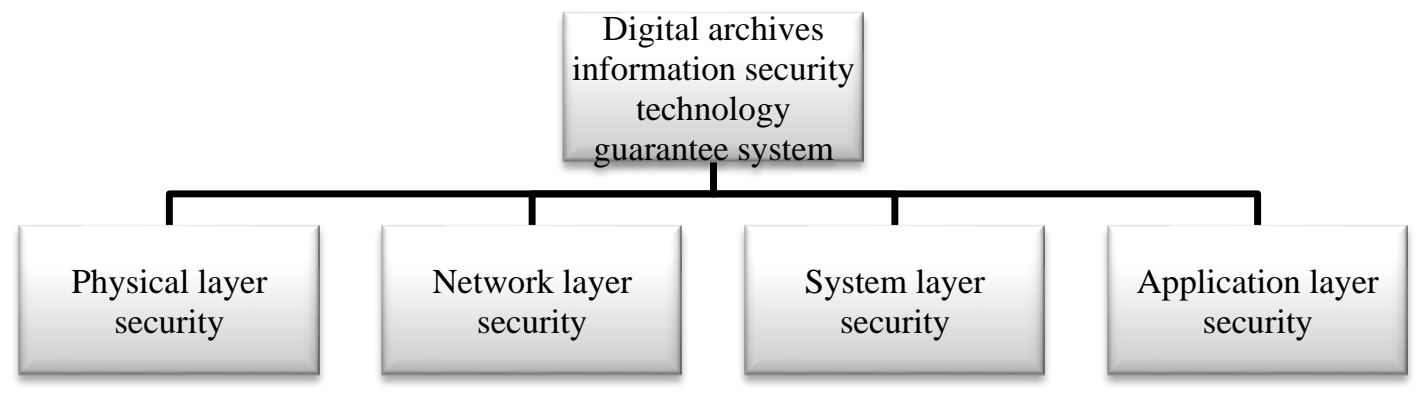

Figure 1: Digital archives information security technology guarantee system

\subsection{Digital fille management personnel are not aware of information security}

With the deepening of the informatization degree of archives, the information security problem of university digital archives becomes more and more serious. On the one hand, due to the lack of awareness of the information security of digital archives in the archives management departments of colleges and universities, the importance and urgency of the security problem is not recognized. For example: only pay attention to file website construction or computer performance, and neglect website security maintenance or security system installation. Due to the weak security awareness of managers, insufficient attention is paid to information security and the neglect of the installation and maintenance of security software, resulting in information security problems. Therefore, improving the security management of digital archives information should start from strengthening the information security awareness of digital archives managers.

\subsection{The security threat of malicious code to digital files in the network environment}

With the continuous advancement of network technology, the development of information applications has been accelerating. Due to the open nature of the Internet, various malicious codes such as viruses and Trojans in the network bring serious threats to various network information security systems. Digital archive information is also developed on the basis of the Internet, so it is also subject to the security threats of various malicious codes in the network. According to relevant statistics, in 2009 alone, the domestic host IP was controlled by Trojans as high as 262,000. The existence of a large number of Trojans poses a serious threat to the archives information system of colleges and universities. In addition, every year, various new types of computer viruses and worms spread in the network, causing serious damage to computer operating systems and important data information. As the famous "flyer" worm that happened before, a large number of private information in the computer system is stolen, and the digital file information of colleges and universities is also threatened by theft ${ }^{[2]}$.

\subsection{Weak talent team in digital file management}

In recent years, with the advancement of science and technology and the continuous development of Internet technology, the digital construction of archives has been continuously 
improved, and the level of digital archive management personnel cannot meet the development requirements of digital archive management, and lacks a professional talent management team. At present, in colleges and universities, many computer personnel engaged in file management do not have a high level of computer operation. In digital file management, it is required to build a full-text database, a multimedia database, and a catalog database of archives. However, the existing archivists in colleges and universities are not aware of the new equipment, technologies and methods in the computer operation and network environment, which seriously impedes the rapid development of the informatization level of digital archives.

\section{Countermeasures for improving the information security of digital archives in colleges and universities}

In the process of digitizing files, due to various factors such as storage media, network environment, hardware devices, and user security awareness, data security is facing more and more threats. Therefore, it is necessary to continuously strengthen the information security construction of digital archives in colleges and universities, improve the information security awareness of digital archives management personnel, establish an information security technology guarantee system for digital archives, and strengthen the construction of a talent team for digital archives information security.

\subsection{Improve the information security awareness of digital file managers}

To improve the information security of digital archives in colleges and universities, we must first improve the information security awareness of digital archives managers, which is the basis for improving the security of digital archives. Only by causing file managers to pay attention to information security will they take various measures to ensure the security and maintenance of file information. Therefore, it is possible to improve the information security awareness of file management personnel through various forms, such as carrying out various information security special lectures, case analysis, business research, and so on, so that file management personnel pay attention to information security issues, so as to improve information security vigilance and prevent the occurrence of information confidentiality and leakage ${ }^{[3]}$.

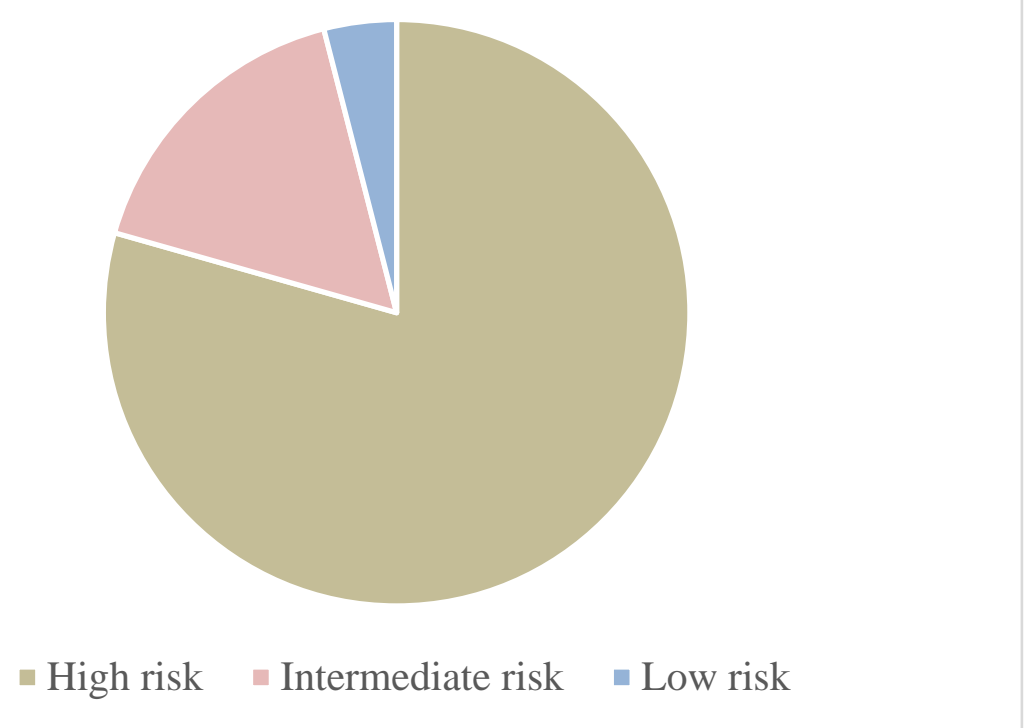

Figure2: Analysis of digital archives information security data in colleges and universities 


\subsection{Establishing an information security technical security system for digital archives}

In today's society where the state attaches great importance to information security, the archivists should attach great importance to the management, security and operation of information technology. Digital archive has the function of remote sharing, and its existence also has huge practical benefits, so that some people or enterprises may illegally obtain some important data information, which is obtained through the network. Therefore, it is necessary to strengthen the emphasis and application of network security technology and establish a network technology guarantee system. Using network security technology to realize information security management of university digital archives, such as setting security password, and using independent equipment for security management. The vulnerability should be checked timely to prevent the invasion of all kinds of viruses and Trojans, and encrypted backup of information data, set identity authentication to prevent the occurrence of potential dangers ${ }^{[4]}$.

\subsection{Strengthening the construction of talent team for digital archive information security}

In order to meet the rapid development requirements of digital archives informationization and improve the management level of digital archives, it is necessary to continuously strengthen the training of professional talents in digital archives management, thus establishing a high-level digital archives management talent team. On the one hand, the existing digital file management personnel in colleges and universities are not regularly trained, and their basic skills in information security management are improved through training. Relevant departments of the school should increase capital investment and formulate relevant training plans. The plan should include modern management information, digital technical information and network technology information, and anti-leakage methods to improve the professional management quality of managers. On the other hand, it is possible to introduce digital archives information security talents at all levels, which is conducive to improving the overall level of the digital archive information security management team ${ }^{[5]}$.

\section{Conclusions}

In a word, digital archives is the future development direction of archives information management in colleges and universities in China. The safety management of university digital archives information is a long and arduous task, involving technology, law, system, consciousness, personnel and other aspects. With the rapid development of social informatization and the rapid development of science and technology, the factors affecting the security of digital archives information are also increasingly numerous. All university archives should attach great importance to and cooperate with each other to constantly improve the efficiency of university archives management, so that the safety management of digital archives information is gradually on a standardized and scientific track, and make due contributions to the permanent safe keeping of archives and the inheritance of history and culture.

\section{References}

[1] Zhang Peng. Research on Digital Archives Security Management System in Colleges and Universities[J]. Lantai World, 2013(29): 91-92.

[2] An Wei. Factors affecting digital archive information security and protective countermeasures [C]// Enterprise Science and Technology Innovation and Management Symposium. 2016.

[3] Gao Binsheng. Countermeasures and Measures for Security Protection of Archives Information System in Colleges and Universities[J]. China Management Information, 2015, 18(23): 169-170. 
[4] Fan Zhendong. Research on Information Security Management of Electronic Construction of Infrastructure in Colleges and Universities[J]. China Management Information, 2014(13): 106-106.

[5] Zhao Li. Factors Affecting Information Security of Digital Archives and Countermeasures[J]. Journal of Decision and Information, 2015(11):261-261. 